\title{
An optimal two-stage distribution of material flow at the fuel and energy complex enterprises
}

\author{
Borys Blyuss ${ }^{1}$, Larysa Koriashkina ${ }^{2}$, Svitlana $\mathrm{Us}^{2}$, Serhii Minieiev ${ }^{1}$, and Serhii Dziuba ${ }^{1, *}$ \\ ${ }^{1}$ Institute of Geotechnical Mechanics named by N. Poljakov of National Academy of Sciences of \\ Ukraine, 49005, Dnipro, Simferopolska Str., 2a, Ukraine \\ ${ }^{2}$ National Technical University «Dnipro Polytechnic», 49005, Dnipro, Dmytra Yavornytskoho Ave., \\ 19, Ukraine
}

\begin{abstract}
The two-stage distributing of material flows in the transportlogistics system of fuel and energy complex is considered. The structural elements of such system are mines (centers of the first stage), extracting coal from various mineral deposits in a certain area, and enterprises that consume or process coal (centers of the second stage). A presented method for solving this problem is based on elements of the theory of continuous linear problems of optimal set partitioning, duality theory, and methods for solving linear programming problems of transport type. The optimal solution of the two-stage location-allocation problem is obtained in an analytical form, which contains parameters that are the optimal solution of the auxiliary finite-dimensional optimization problem with a nondifferentiable objective function. Therefore, the part of numerical algorithm is non-differentiable optimization method - modification of Shor's r-algorithm. The results of computational experiments solving model problems confirm the correctness of the presented method and algorithm. It is demonstrated the synergistic effect obtained from formulation of continuous problems of optimal partitioning sets with additional constraints. It is showed, how important to take into account the multi-stage distributing of raw materials when it is necessary to locate new transport-logistics system objects in a given territory.
\end{abstract}

\section{Introduction}

Sustainable development of the fuel and energy complex (FEC) of the country is the most important component of the national energy security and the long-term prospect of Ukraine's economic growth. In the development of the productive forces of the country, the fuel and energy complex plays an ever-increasing role, which is caused, on the one hand, by global trends, and on the other, by the energy capacity of the national economy and the limited energy resources of the region. The development of the fuel and energy sector largely determines the dynamics, scope and technical and economic indicators of industry and social production in general. Power industry significantly affects not only development, but also the territorial organization of the national economy.

An important role in the fuel and energy complex of Ukraine belongs to the mining

${ }^{*}$ Correspondent author: sergejdzuba@gmail.com 
industry, since coal reserves are potentially sufficient to almost fully meet the needs of the country's national economy. And, as noted in [1], the use of currently explored coal reserves in combination with science-based technologies at the stages of mining, enrichment, processing and using of fuel and energy, will ensure the country's energy security without the involvement of foreign energy resources. And the extraction of potential benefits from the development of fuel resources is possible only if there is a longterm, responsible approach to the development of the mining industry.

Under the conditions of an underground mining enterprise, material flows are a (interconnected in a special way) set of logistic operations, processes, links and items from preparing the field for development, mining and processing of material resources and ending with consumption (redistribution) of finished products to achieve the overall goals of the logistic system. Logistic systems of the mines are inextricably connected with the flow processes of enterprises within the system of manufacturing associations. In the fuel and energy complex logistics systems, the warehouse is actually an intermediate link between a mining enterprise and coal consumers, and it is considered as a production element [2].

In general, transport and logistics systems of the fuel and energy complex, where the processes of circulation of material resources are implemented, are quite capacious and complex, as they are characterized by a large number of business entities and intermediaries located in different regions and over large territories, with different demand from different consumers, many other factors that predetermine the characteristics of the organization of the process of movement of material resources.

The object of the research is a two-stage process of distribution of material flows in the transport and logistics system, the structural elements of which are mines (hereinafter - the centers of the first stage), producing coal, continuously distributed in a certain area, and enterprises that consume or process coal (centers of the second stage). As known, the territory (zone) of production is assigned to each mine. The movement of raw materials is carried out first in the direction from each point of the zone under consideration directly to the place of its accumulation at the corresponding mine, and then the sorted resource is sent in certain quantities to the enterprises acting as consumers - combined heat and power (CHP), concentrating factories and other entities.

The subject of the research is mathematical models and algorithms for solving multistage resource distribution problems, where the resource is distributed continuously in a given area. The purpose of the work is to ensure reduction of transport costs at the enterprises of the fuel and energy complex associated with the extraction of coal in a given area and its delivery to the warehouses of the respective mines, and then to the final consumers. The relevance of the work is explained by one of the most pronounced trends in the mining and processing industries - the creation of geographically distributed multi-level companies, including dozens of large enterprises and carrying out a full production cycle from the extraction of raw materials with its integrated use and processing to transportation to end users.

\section{Statement of the problem}

Consider a certain area with known reserves of raw materials (coal), location of functioning mines (centers of the first stage) and zone of their extraction. Coal accumulates in the places of shipment in mines and is sent to the processing plants and CHP (enterprises of the second stage). Existing mines have limited production capacity (due to the equipment deterioration over time or the exhaustion of resources) and cannot fully meet the needs for raw materials of a second-stage enterprise. Hence, there is a need to search for areas to open new mines (one or more) in a given territory, to determine the areas of their coal 
mining services (production), as well as the amount of re-sorted raw materials transported from all the mines to the second stage enterprises (Fig. 1).

The mathematical model of the described situation is a two-stage problem of optimal partitioning of sets with additional constraints (OPSAC) [3, 4]. For its formulation, we introduce the following notation: $\Omega$ - an certain area on which the resource is distributed, and where the first-stage centers can be located, $\mathrm{m}^{2} ; \rho(x)$ - resource reserves in each point $x$ of $\Omega$ area, $\mathrm{t} / \mathrm{m}^{2} ; N$ - number of first-stage centers; $M$ - number of second-stage centers; $S$ - total quantity of resource in a given area, $\mathrm{t} ; \tau_{i}^{r}-$ coordinates of $r$ - stage $i$ center; $b_{i}^{r}$ - cardinality of $r$-stage $i$-center, $r=I, I I, \mathrm{t} ; c_{i}^{I}\left(x, \tau_{i}^{I}\right)$ - resource unit delivery cost from point $x \in \Omega$ to center $\tau_{i}^{I}, \mathrm{UAH} / \mathrm{t} ; c_{i j}^{I I}\left(\tau_{i}^{I}, \tau_{j}^{I I}\right)$ - unit delivery cost from center $\tau_{i}^{I}$ to center $\tau_{j}^{I I}, \mathrm{UAH} / \mathrm{t} ; a_{i}-$ resource sorting and shipment cost in the center $\tau_{i}^{I}, \mathrm{UAH} / \mathrm{t} ; v_{i j}$ - resource amount delivered from the center $\tau_{i}^{I}$ to center $\tau_{j}^{I I}$, t.

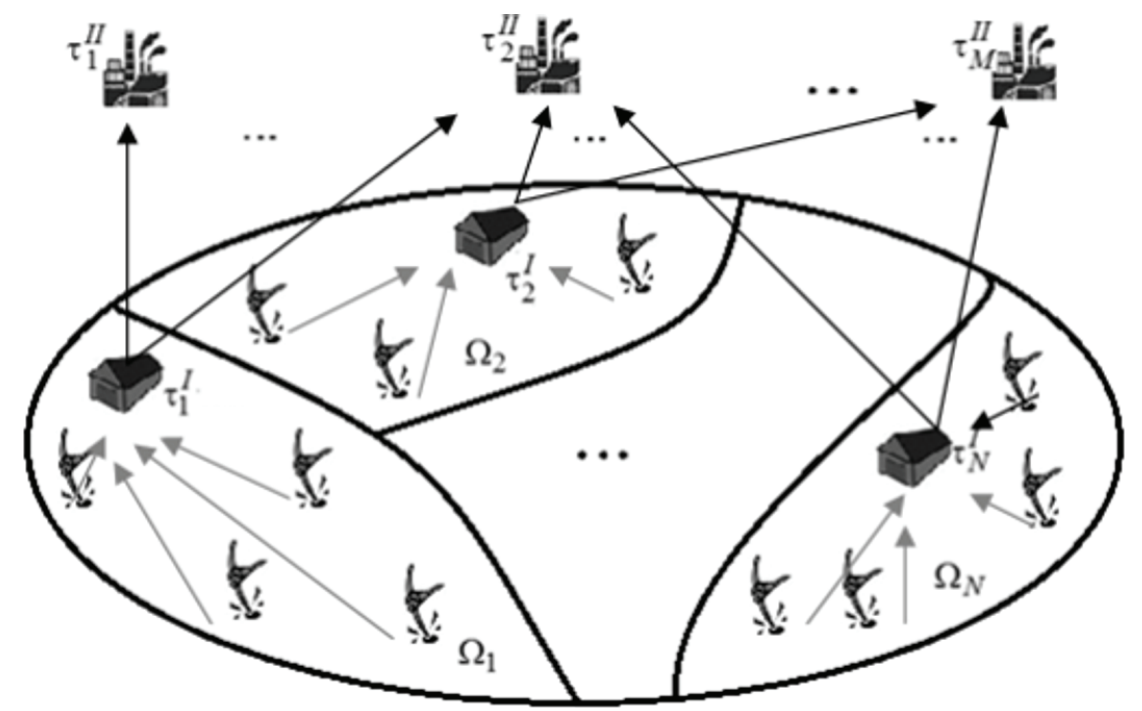

Fig. 1. Scheme of material flows distribution in the two-stage continuous optimal location - allocation problem.

Problem A. To find such partition of set $\Omega$ into $N$ disjoint subsets $\bar{\omega}=\left\{\Omega_{1}, \Omega_{2}, \ldots, \Omega_{N}\right\}$ (some of which can be empty), to determine coordinates of its centers $\tau_{1}^{I}, \ldots, \tau_{N}^{I}$ and supply volumes $v_{11}, \ldots, v_{N M}$, under which the functional

$$
F\left(\bar{\omega}, \tau^{I}, v\right)=\sum_{i=1}^{N} \int_{\Omega_{i}} c_{i}^{I}\left(x, \tau_{i}^{I}\right) \rho(x) d x+\sum_{i=1}^{N} \sum_{j=1}^{M}\left(c_{i j}^{I I}\left(\tau_{i}^{I}, \tau_{j}^{I I}\right)+a_{i}\right) \nu_{i j}
$$

would have reached a minimum value, and the following conditions were satisfied:

$$
\begin{aligned}
& \int_{\Omega_{i}} \rho(x) d x=\sum_{j=1}^{M} v_{i j}, \quad i=\overline{1, N}, \\
& \sum_{i=1}^{N} v_{i j}=b_{j}^{I I}, \quad j=\overline{1, M}, \\
& \bar{\omega} \in \Sigma_{\Omega}^{N}, \quad v \in R_{N M}^{+}, \quad \tau^{I} \in \Omega^{N},
\end{aligned}
$$




$$
\Sigma_{\Omega}^{N}=\left\{\bar{\omega}=\left\{\Omega_{1}, \Omega_{2}, \ldots, \Omega_{N}\right\}: \bigcup_{i=1}^{N} \Omega_{i}=\Omega, \operatorname{mes}\left(\Omega_{i} \cap \Omega_{j}\right)=0, i \neq j, i, j=\overline{1, N}\right\},
$$

where $\Sigma_{\Omega}^{N}$ - the class of all possible partitions of the set $\Omega$ into $N$ disjoint subsets; $\bar{\omega}=\left\{\Omega_{1}, \Omega_{2}, \ldots, \Omega_{N}\right\}-$ element of class $\Sigma_{\Omega}^{N} ; R_{N M}^{+}-N M$ - dimensional space of nonnegative real numbers.

If the centers $\tau_{1}^{I}, \ldots, \tau_{N}^{I}$ are known in advance, we formulate a continuous problem of optimal partitioning of the set for fixed centers of subsets.

\section{Review of scientific publications}

Many domestic scientific papers, in particular [1, 2, 5 - 7, etc.], and works of foreign scientists, for example, [8 - 24], were dedicated to optimizing supply volumes and to developing of mechanisms for reducing the total costs of stockpiling at mining enterprises.

The mechanisms of supply chain management in systems of the fuel and energy complex of Ukraine were studied in $[1,5]$.

In [2], the authors solve the problem of determining the current value of the coal stock in the warehouse, considering financial losses, caused by the fact that during long-term storage of coal in the warehouse, it loses its consumer qualities, in addition, there is a need to increase the cost on coal moving to prevent its blocking property.

In [6], on the basis of mathematical modeling of the operation of conveyor transport of coal mines, an algorithm for determining the average energy intensity of transportation of the rock mass was developed. It reveals that the most significant parameters affecting the efficiency of the underground conveyor transport of coal mines are the values of cargo flows from lavas, the performance of feeders, the volume of bunkers and the cost of electricity.

The methodological foundations of the logistic intellectual management of industrial complexes and projects on their creation are presented in [7].

The paper [8] is dedicated to the analysis of the optimal locations and scale of fossil fuel-fired power plants to reduce the consumption of fossil carbon in the Japanese energy sector under several scenarios of electricity demand. It is shown that, from the intraregional point of view, fossil fuel power plants can be built in areas with high demand for electricity. In addition, with the exception of the areas mentioned above, output from fossilfueled power plants will vary depending on the availability of renewable energy sources and the demand for electricity. It was noted that the future climate policy, regional demand for electricity and the availability of regional renewable energy sources should be considered when planning the development of industrial complexes.

In [9], a method for creating schedules of extraction, processing and transportation, that take into account changes in working conditions at the current stage of processing or during transportation, was developed. In this method, the solution found using conventional optimizers is enhanced by disturbances associated with three different levels of decision making: disturbances based on the size of the mined blocks, disturbances based on alternative processing options (fine or coarse grinding) and disturbances based on the transport system.

A broad review of research papers studying logistical problems at mining enterprises is presented in [10]. The mining complex is interpreted as a supply chain system in which material is transformed from one activity to another. The main activities (or stages) include: extraction of materials from one or several sources (deposits); mixing material with the accumulation in mind; processing of the material along various processing paths taking into 
account several operational alternatives; and transportation of products to the port or to end consumers using one or more transport systems.

Recent developments in the field of modeling and optimization of approaches to the extraction of mineral and energy resources have led to the emergence of new systems of simultaneous stochastic optimization and the corresponding digital technologies. The mining complex is a type of value chain, according to which raw materials (minerals) extracted from various mineral deposits are converted into a set of products to sell using available processing flows. The supply of materials mined from a group of mines is a major source of uncertainty in the mining industry and the minerals value chains. The simultaneous stochastic optimization of mining complexes presented in this paper aims to eliminate the main restrictions of past approaches by modeling and optimizing several interrelated aspects of the minerals value chain in one model. This unified optimization model combines the extraction of material from a set of sources along with their uncertainty, associated with this risk management, mixing, accumulation, non-linear transformations that occur in the available processing flows, using processing flows and, finally, transporting products to customers.

Despite the large number of scientific works on the optimization and development of fuel and energy complexes and their industries, the issues of balancing raw material flow at the current stage of development of the FEC remain open.

In contrast to [10], where a two-stage stochastic mixed nonlinear integer programming problem is used to model and optimize a mining complex, in $[9,11,12]$, when formulating multi-stage allocation-distribution problems, it is assumed that the initial resource occupies some territory (densely). In this case, mathematical models become continuous and represent problems of infinite-dimensional programming. The continuity of the problem formulated in the paper is also caused by the possibility of locating the centers of the first stage at any point of a given continual set.

This paper demonstrates the possibility of using mathematical software developed for solving continuous multi-stage problems of optimal partitioning of sets with additional links in the organization of logistics systems in the mining industry.

\section{Methods}

We assume that for the problem (1) - (5) the condition

$$
\sum_{j=1}^{M} b_{j}^{I I}=\int_{\Omega} \rho(x) d x
$$

are fulfilled. Under (6) the set of all possible partitions (that satisfying the conditions (2), (3)) is no empty.

We shall take a quick look at the idea of solving method. In accordance with the theory of linear continuous problems of optimal partitioning of sets [11], the initial problem (1) (5) is written in an equivalent form as the infinite-dimensional mathematical programming problem with Boolean variables.

Let vector-function $\lambda(\cdot)=\left(\lambda_{1}(\cdot), \ldots, \lambda_{N}(\cdot)\right)$ consists of the characteristic functions of the subsets that form a partition of the set $\Omega$ :

$$
\lambda_{i}(x)= \begin{cases}1, & x \in \Omega_{i}, \\ 0, & x \in \Omega \backslash \Omega_{i}, \quad i=\overline{1, N} .\end{cases}
$$

Problem B. Find 


$$
\begin{gathered}
\min _{\left(\lambda(\cdot), \tau^{I}, v\right) \in \Gamma \times \Omega^{N} \times R_{N M}^{+}} I\left(\lambda(\cdot), \tau^{I}, v\right), \\
I\left(\lambda(\cdot), \tau^{I}, v\right)=\sum_{i=1}^{N} \int_{\Omega} c_{i}^{I}\left(x, \tau_{i}^{I}\right) \rho(x) \lambda_{i}(x) d x+\sum_{i=1}^{N} \sum_{j=1}^{M}\left(c_{i j}^{I I}\left(\tau_{i}^{I}, \tau_{j}^{I I}\right)+a_{i}\right) \nu_{i j}, \\
\sum_{i=1}^{N} v_{i j}=b_{j}^{I I}, \quad j=\overline{1, M}, \\
\int_{\Omega} \rho(x) \lambda_{i}(x) d x=\sum_{j=1}^{M} v_{i j}, \quad i=\overline{1, N}, \\
\Gamma=\left\{\lambda(x)=\left(\lambda_{1}(x), \ldots, \lambda_{N}(x)\right): \lambda_{i}(x)=0 \vee 1, i=\overline{1, N}, \sum_{i=1}^{N} \lambda_{i}(x)=1 \text { a.e. for } x \in \Omega\right\} .
\end{gathered}
$$

Further it is carried out a problem reduction considering the function values $\lambda_{i}(x)$ on the segment $[0 ; 1], i=\overline{1, N}$.

Problem C. Find

$$
\begin{gathered}
\min _{\left(\lambda(\cdot), \tau^{I}, v\right) \in \Gamma_{0} \times \Omega^{N} \times R_{N M}^{+}} I\left(\lambda(\cdot), \tau^{I}, v\right), \\
I\left(\lambda(\cdot), \tau^{I}, v\right)=\sum_{i=1}^{N} \int_{\Omega} c_{i}^{I}\left(x, \tau_{i}^{I}\right) \rho(x) \lambda_{i}(x) d x+\sum_{i=1}^{N} \sum_{j=1}^{M}\left(c_{i j}^{I I}\left(\tau_{i}^{I}, \tau_{j}^{I I}\right)+a_{i}\right) \nu_{i j}, \\
\sum_{i=1}^{N} v_{i j}=b_{j}^{I I}, \quad j=\overline{1, M}, \\
\int_{\Omega} \rho(x) \lambda_{i}(x) d x=\sum_{j=1}^{M} v_{i j}, \quad i=\overline{1, N}, \\
\Gamma_{0}=\left\{\lambda(x)=\left(\lambda_{1}(x), \ldots, \lambda_{N}(x)\right): 0 \leq \lambda_{i}(x) \leq 1, i=\overline{1, N}, \sum_{i=1}^{N} \lambda_{i}(x)=1 \text { a.e. for } x \in \Omega\right\} .
\end{gathered}
$$

Since the set of optimal solutions of Problem C contains optimal solutions of Problem $\mathrm{B}$, the solving of Problem B is reduced to solving Problem C and selecting from all its optimal solutions those that are also solutions of Problem B.

It's proved [12], if in Problem A function $\rho(x) \geq 0$ a.e. for $x \in \Omega$, and parameters $b_{1}^{I I}, b_{2}^{I I}, \ldots, b_{M}^{I I}$ satisfy conditions (6), then in order to an optimality of a possible partition $\left(\Omega_{*_{1}}, \Omega_{*_{2}}, \ldots, \Omega_{*_{N}}\right) \in \Sigma_{\Omega}^{N}$ of the set $\Omega$ for Problem A, it is necessary and sufficient existence real constants $\psi_{1}, \psi_{2}, \ldots, \psi_{N}$ such that

$$
c_{i}^{I}\left(x, \tau_{i}^{I}\right)+\psi_{i} \leq c_{k}^{I}\left(x, \tau_{k}^{I}\right)+\psi_{k}, i \neq k, \text { a.e. for } x \in \Omega_{*_{i}}, i, k=1, \ldots, N .
$$

At points $x$, belonging to the optimal boundary of subsets $\Omega_{*_{i}}$ and $\Omega_{*_{k}}$, the equality sign is attained in inequality (7). 
An optimal solution of the Problem $C$, subject to $\rho(x) \geq 0$ a.e. for $x \in \Omega$ and (6), is written like this: for $i=1, \ldots, N$ and $x \in \Omega$

$$
\lambda_{*_{i}}(x)=\left\{\begin{array}{l}
1, \text { if } c_{i}^{I}\left(x, \tau_{*_{i}}^{I}\right)+\psi_{i}^{*} \leq c_{k}^{I}\left(x, \tau_{*_{k}}^{I}\right)+\psi_{k}^{*}, \\
\quad i \neq k, \text { a.e. for } x \in \Omega, i, k=1, \ldots, N, \text { then } x \in \Omega_{*_{i}}, \\
0 \quad \text { in the other cases, }
\end{array}\right.
$$

where $\tau_{*_{i}}^{I}, \psi_{i}^{*}, i=1, \ldots, N,-$ optimal solution of the following problem:

$$
\begin{gathered}
G(\psi) \rightarrow \max , \quad \psi \in R^{N}, \\
G(\psi)=\min _{\left(\left\{\tau^{I}, v\right\}, \psi\right) \in \Omega^{N} \times R_{N M}^{+}} G_{1}\left(\left\{\tau^{I}, v\right\}, \psi\right), \\
G_{1}\left(\left\{\tau^{I}, v\right\}, \psi\right)=\int_{\Omega} \min _{k=1, N}\left(c_{k}^{I}\left(x, \tau_{k}^{I}\right)+\psi_{k}\right) \rho(x) d x+\sum_{j=1}^{M} b_{j} \max _{i=1, N}\left(\psi_{i}-c_{i j}^{I I}\left(\tau_{i}^{I}, \tau_{j}^{I I}\right)-a_{i}\right) .
\end{gathered}
$$

If in the problem A the first stage centers $\tau_{1}^{I}, \ldots, \tau_{N}^{I}$ are given, it is proved, that the necessary and sufficient condition for the optimality of the pair $\left\{\lambda^{*}(\cdot), v^{*}\right\} \in \Gamma_{0} \times R_{N M}^{+}$in conforming problem $\mathrm{B}$ is existence of such real constants $\psi_{i}^{*}, i=1, \ldots, N$, and $\eta_{j}^{*}, j=1, \ldots, M$, under which the following conditions are satisfied:

1) for all $i=1, \ldots, N$ and almost all $x \in \Omega$

$$
\lambda_{*_{i}}(x)=\left\{\begin{array}{l}
1, \text { if } c_{i}^{I}\left(x, \tau_{*_{i}}^{I}\right)+\psi_{i}^{*}=\min _{k=1, N}\left(c_{k}^{I}\left(x, \tau_{*_{k}}^{I}\right)+\psi_{k}^{*}\right), \\
0 \quad \text { in the other cases, } i=1, \ldots, N
\end{array}\right.
$$

2) for all $i=1, \ldots, N$ and $j=1, \ldots, M$

$$
\left\{\begin{array}{l}
c_{i j}^{I I}\left(\tau_{i}^{I}, \tau_{j}^{I I}\right)+a_{i}=\psi_{i}^{*}+\eta_{j}^{*}, \text { if } v_{i j}^{*}>0 \\
c_{i j}^{I I}\left(\tau_{i}^{I}, \tau_{j}^{I I}\right)+a_{i}>\psi_{i}^{*}+\eta_{j}^{*}, \text { if } v_{i j}^{*}=0
\end{array}\right.
$$

The components $v_{i j}^{*}$ - optimal solution of such transportation problem:

$$
\begin{gathered}
\sum_{i=1}^{N} \sum_{j=1}^{M}\left(c_{i j}^{I I}\left(\tau_{i}^{I}, \tau_{j}^{I I}\right)+a_{i}\right) v_{i j}^{*} \rightarrow \min , \\
\sum_{j=1}^{M} v_{i j}=b_{i}^{I^{*}}, b_{i}^{I^{*}}=\int_{\Omega} \rho(x) \lambda_{i}^{*}(x) d x, \quad i=\overline{1, N}, \\
\sum_{i=1}^{N} v_{i j}=b_{j}^{I I}, \quad j=\overline{1, M} \\
v_{i j} \geq 0, i=1, \ldots, N ; j=1, \ldots, M .
\end{gathered}
$$


Dual variables $\psi_{i}$ and $\eta_{j}$, as in classical problems of transport type, are called potentials of center $\tau_{i}^{I}$ and $\tau_{j}^{I I}$ respectively.

In [12], an iterative algorithm was proposed for solving Problem A with fixed centers. This algorithm, developed on formulas (9) and (10) under the assumption $\rho(x) \geq 0$ for all $x \in \Omega$, has been modified to locate the first stage centers.

The numerical solving of the formulated OPSAC problem based on the above necessary and sufficient optimality conditions involves recording the problem (8) in the following form:

$$
\begin{aligned}
& \max _{\psi \in R^{N}} G(\psi)=\max _{\psi \in R^{N}} \min _{\left.\left\{\tau^{I}, v\right\}, \psi\right) \in \Omega^{N} \times R_{N M}^{+}} G_{1}\left(\left\{\tau^{I}, v\right\}, \psi\right)=\min _{\left(\left\{\tau^{I}, v\right\}, \psi\right) \in \Omega^{N} \times R_{N M}^{+}} \max _{\psi \in R^{N}} G_{1}\left(\left\{\tau^{I}, v\right\}, \psi\right)= \\
& =\min _{\tau^{I} \in \Omega^{N}} \min _{v \in \times R_{N M}^{+}} \max _{\psi \in R^{N}} G_{1}\left(\left\{\tau^{I}, v\right\}, \psi\right)=\min _{\tau^{I} \in \Omega^{N}} Q\left(\tau^{I}\right),
\end{aligned}
$$

where

$$
Q\left(\tau^{I}\right)=\min _{v \in \times R_{N M}^{+}} \max _{\psi \in R^{N}} G_{1}\left(\left\{\tau^{I}, v\right\}, \psi\right)
$$

Given arbitrary fixed values $\tau^{I} \in \Omega^{N}$ the value $Q\left(\tau^{I}\right)$ is an optimum of the dual functional, which constructed for a continuous OPSAC with fixed centers and formulated in terms of the characteristic functions of subsets. The key role is assigned to the method of generalized gradient ascent with space dilatation in the direction of the difference of two sequential gradients, i.e., the $-r$ - algorithm of Shor, with the help of which the search local unconditional minima of non-smooth functions is carried out.

The constraints $\tau^{I} \in \Omega^{N}$ may be accounted by the operator of projection $P_{\Omega^{N}}$, if set $\Omega$ - convex, closed, and has a rather simple structure that does not call solving the auxiliary problem of conditional optimization for finding the projection of a point on the set. If structure of $\Omega$ is rather complicated, then its form should be described by inequality constraints. For keeping track of such constraints, in turn, non-smooth penalty functions can be used.

\section{Results of computational experiments}

The algorithm for solving a two-stage continuous OPSAC with the placement of the first stage centers is implemented. Under numerically implementation a given region is discretized. To calculate multiple integrals in the developed program, the cubature formula of trapezium is used; problem (11) - (14) is solved using the method of potentials.

Testing the validity of the theory and algorithm was carried out by solving many model problems. Here results some of them, in which $\Omega=\{(x, y): 0 \leq x \leq 1 ; 0 \leq y \leq 1\}$, are presented. Without generality loss, it is assumed that both the first and second stages of the enterprise belong to the region $\Omega$.

In all the above experiments: $\varepsilon_{1}=\varepsilon_{2}=0.0001$, parameters of $r$-algorithm $\alpha=3, \beta=0.9$, $\varepsilon=0.0001 ; \quad \rho(x)=1$ for all $x \in \Omega ; \quad a_{i}=0 \forall i=\overline{1, N} ;$ for all $i=\overline{1, N}, j=\overline{1, M}$, $c_{k}^{I}\left(x, \tau_{k}^{I}\right)=\sqrt{\left(x_{1}-\tau_{1 k}^{I}\right)^{2}+\left(x_{2}-\tau_{2 k}^{I}\right)^{2}}, c_{k j}^{I}\left(\tau_{k}^{I}, \tau_{j}^{I I}\right)=\sqrt{\left(\tau_{1 k}^{I}-\tau_{1 j}^{I I}\right)^{2}+\left(\tau_{2 k}^{I}-\tau_{2 j}^{I I}\right)^{2}}$. 
At first we have experimented with such initial data: $N=M=2$; region discretization grid $-101 \times 101=10201 ; b^{I I}=(0.5 ; 0.5) ; \tau_{1}^{I I}=(0.25 ; 0.5), \tau_{2}^{I I}=(0.75 ; 0.5)$; approximation of first stage centers $\tau_{1}^{I(0)}=(0.1 ; 0.3), \tau_{2}^{I(0)}=(0.8 ; 0.6)$. The optimal solution was obtained at the 58th $r$-algorithm iteration. It corresponds to the following values of the desired values: $\tau_{1}^{I^{*}}=(0.263 ; 0.498), \tau_{2}^{I^{*}}=(0.752 ; 0.502) ; v_{11}^{*}=0.5, v_{12}^{*}=0.0168, v_{22}^{*}=0.4832 ; I=0.3039$. The optimal partitioning and placement of centers are presented in Figure 2,a.

As can be seen from the figure, the first stage centers were placed almost at the same points as the specified centers of the second stage, and the classical Dirichlet - Voronoi diagram for these points turned out to be the optimal partitioning of the unit square. By a simple industrial management rule, any production unit should be located closest to the source of raw materials or the market, or to both, if possible.

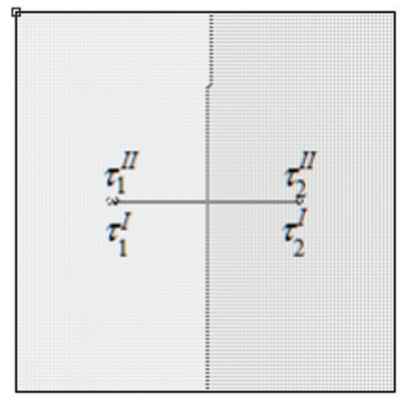

a)

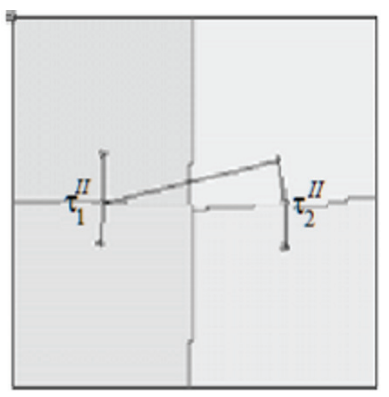

b)

Fig. 2. Optimal partition of set $\Omega$ and communication scheme in OPSAC with the placement of $N$ first stage centers: a) $-N=2 ;$ b) $-N=4$.

Such principle can be traced in Figure 2,b and Figure 3. Here are the results of the optimal locating of 4 and 6 first stage centers and the corresponding partitioning of a given set, considering the additional connections of these centers with two (Fig. 2,b and Fig. 3,a) and nine (Fig. 3,b) second stage centers.

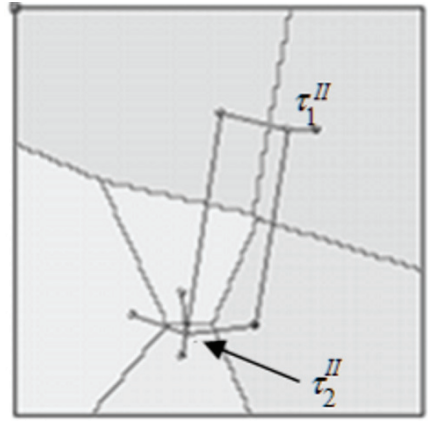

a)

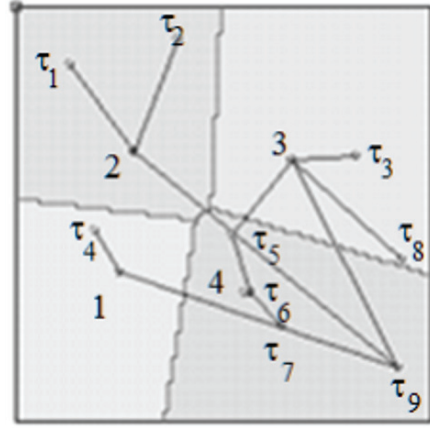

b)

Fig. 3. Optimal partition of set $\Omega$ and communication scheme in OPSAC problem: a) $-N=6$, $\left.M=2, b^{I I}=(0.5 ; 0.5) ; \mathrm{b}\right)-N=4, M=9, b^{I I}=(0.1 ; 0.12 ; 0.1 ; 0.12 ; 0.09 ; 0.1 ; 0.1 ; 0.1 ; 0.16)$.

In [11], it is noted that in the conditions of the model problem 1 points $\tau_{i}^{I}$, obtained as a solution of OPSAC problem, as well as a pair of points $(0.5 ; 0.25)$ and $(0.5 ; 0.75)$, together with their Dirichlet-Voronoi diagrams are global optima of the continuous problem of optimal partitioning of sets (SPP) with the placement of subset centers. The objective functional calculated by solving model problem 1 differs from the global minimum of the functional in the problem of partitioning a unit square by $\delta=0.3039-0.2966=0.0073$. 
Consequently, it may be deduced that algorithm works correctly and obtained solution is global optima (with acceptable precision).

The expediency of setting and solving OPSAC problems in the formation of two-stage transportation systems with material (raw) resources, continuously occupied a certain territory, is confirmed by solving of the following model problem.

Let the resource be uniformly distributed on the same unit square. It is necessary to divide the square into 10 zones, locate the corresponding first stage centers and determine their possible connections with the two second stage centers, which consumption volumes are $b^{I I}=(0.5 ; 0.5)$, so as to minimize the total costs of delivering the resource to the first stage centers, as well as the of resource transporting cost to the second stage centers. Figure 4 ,a shows the location of the second stage centers. It also presents the optimal location of the first stage centers, the corresponding service areas, and indicates additional communications between the enterprises of the first and second stages. The value of the target functional in this location-distribution problem is $I=0.33069$.

Figure 4,b illustrates the optimal placement of the first stage centers and the corresponding zones obtained during the implementation of the next approach. First, we solved the SPP problem with the placement of centers and the partition quality criterion equal to the first term of the functional (1), and then with the obtained coordinates of the first stage centers, we solved the transport type problem with the criterion equal to the second term in (1).

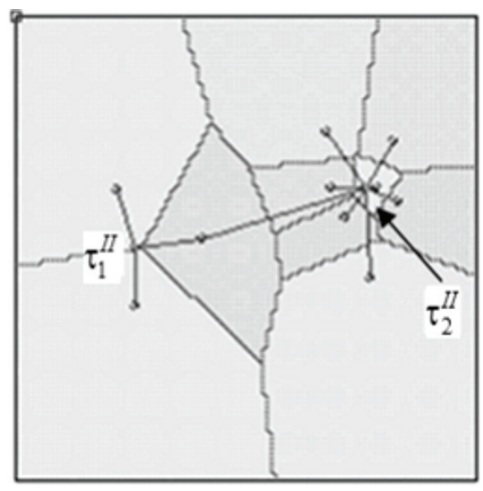

a)

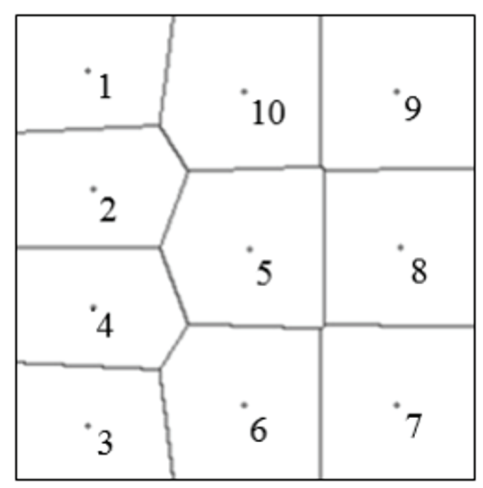

b)

Fig. 4. Optimal partition of set $\Omega$ and optimal location of centers in the problem: a) - SPP with additional constraints; $b$ ) - SPP with locating of subsets centers.

The sum of the target functionals is equivalent to

$$
I_{1}+I_{2}=0.1222+0.300964=0.423164 .
$$

It is significantly more than the optimal value of the quality criterion of the OPSAC problem. And, thus, the given example shows how important for obtaining a synergistic effect to formulate optimization problems for two-stage logistic processes with a continuously distributed resource in the form of problem (1) - (5).

\section{Conclusion}

The research addresses an urgent problem related to the optimal organization of two-stage processes for the distribution of material flows in the transport and logistics system, the structural elements of which are mines that produce coal in a certain area and enterprises that consume or recycle this resource. 
The study of the organization of two-stage tasks for distribution of raw material flows at the enterprises of the fuel and energy complex was carried out in accordance with such general methodological principles as the system approach, the principle of total costs, the principle of global optimization.

All elements of a two-stage logistics system are considered as interconnected and interacting to achieve the common goal of the functioning of the system. Functioning optimization was performed not for individual elements, but for the logistic system in general. At the same time, the total amount of costs associated with the management of material and connected service and financial flows throughout the logistics chain, starting from the moment of inception of the flow until it arrives at the final consumer, was considered. And, thus, the local interests and goals of functioning of individual elements of the system were coordinated with the main objective function of the whole system - the achievement of optimal transport and associated costs of the entire two-stage logistics system. The use of the approach described in the paper allows to purposefully form the mechanism for managing the system for promoting flows of produced and raw materials of the mining system (open pit, underground mine, concentration plant).

Prospects for further research are development of software for solving multi-stage allocation-distribution problems arising at enterprises of the fuel and energy complex with the involvement of GIS technologies.

\section{References}

1. Puhanov, A.A. (2009). Logisticheskie problemyi v upravlenii transportnoy sistemoy predpriyatiy toplivno-energeticheskogo kompleksa. Visnyk Donetskoho instytutu avtomobilnoho transportu, 1, 251-257

2. Budishevskiy, V.A., Puhanov, A.A., Puhanova, L.S. (2005). Ekonomicheskie aspektyi upravleniya zapasami uglya $\mathrm{v}$ logisticheskih sistemah toplivno-energeticheskogo kompleksa. Nauchnyie trudyi DonNTU. Seriya: ekonomicheskaya. 100 (1), 173-178

3. Us, S.A., Stanina, O.D. (2015). On some mathematical models of facility location problems of mining and concentration industry. New Developments in Mining Engineering Theoretical and Practical Solutions of Mineral Resources Mining, 419-424

4. Us, S.A., Stanina, O.D. (2017). Modelirovanie protsessa razmescheniya obogatitelnogo proizvodstva s uchetom nepreryivno raspredelennogo resursa. Zbirnyk naukovykh prats, 52, 314-323

5. Puhanov, A.A. (2007). Upravlenie tsepyami postavok uglya $\mathrm{v}$ sistemah toplivnoenergeticheskogo kompleksa. Ekonomika: problemy teorii ta praktyky. Zbirnyk naukovykh prats, 225 (1), 431-437

6. Kiriya, R.V. (2014). Opredelenie energeticheskoy effektivnosti sistem podzemnogo konveyernogo transporta ugolnyih shaht. Heotekhnichna mekhanika. 119, 125-135

7. Fedorovich, O.E., Maleeva, O.V., Druzhinin, E.A., Prohorov, A.V. (2005). Razrabotka metodologicheskih osnov logisticheskogo intellektualnogo upravleniya proizvodstvennyimi kompleksami i proektami po ih sozdaniyu. Aviatsionnokosmicheskaya tehnika i tehnologiya, 7 (23), 338-351

8. H. Shiraki, S. Ashina, Y. Kameyama, S. Hashimoto, T. Fujita, Analysis of optimal locations for power stations and their impact on industrial symbiosis planning under transition toward low-carbon power sector in Japan. Journal of Cleaner Production, 114 (2015)

9. L. Montiel, R. Dimitrakopoulos, Optimizing mining complexes with multiple processing and transportation alternatives: An uncertainty-based approach. European Journal of Operational Research, 247, 1 (2015) 
10. R. Goodfellow, , R. Dimitrakopoulos, Simultaneous Stochastic Optimization of Mining Complexes and Mineral Value Chains. Mathematical Geosciences, 49, 3 (2017)

11. Kiseleva, E.M., Korjashkina, L.S., Us, S.A. (2015). Teorija optimal'nogo razbienija mnozhestv $\mathrm{V}$ zadachah raspoznovanija obrazov, analiza i identifi-kacii sistem: monografija. M-vo obrazovanija $i$ nauki Ukrainy, GVNZ "Nac. gorn. un-t". Dnepropetrovsk: NGU

12. Zelentsov, D., Us, S., Koryashkina, L., Stanina, O. (2017). Solving Continual TwoProblems of Optimal Partition of Sets Stage. International Journal of Research Studies in Computer Science and Engineering (IJRSCSE). 4 (4), 72-80 